\title{
Arro, Calcatoggio
}

2013 - Prospection diachronique $\mathrm{n}^{\circ} 1269$

Marie-Andrée Gardella

\section{(2) OpenEdition}

Journals

Édition électronique

URL : http://journals.openedition.org/adlfi/15657

ISSN : 2114-0502

Éditeur

Ministère de la culture

Référence électronique

Marie-Andrée Gardella, «Arro, Calcatoggio », ADLFI. Archéologie de la France - Informations [En ligne], Corse, mis en ligne le 26 avril 2017, consulté le 03 mai 2019. URL : http://journals.openedition.org/ adlfi/15657

Ce document a été généré automatiquement le 3 mai 2019.

(c) Ministère de la Culture et de la Communication, CNRS 


\title{
Arro, Calcatoggio
}

$n^{\circ} 1269$

\author{
Marie-Andrée Gardella
}

Lien Atlas (MCC) :

http://atlas.patrimoines.culture.fr/atlas/trunk/index.php?

ap_theme=DOM_2.01.02\&ap_bbox=8.774;42.081;8.828;42.114

1 Au cours de l'année 2013, nous avons mené une prospection-inventaire diachronique sur les communes d'Arro et de Calcatoggio. Ces deux communes font parties des sept communes composant la micro-région de la Cinarca. Cette prospection fait suite à un travail commencé en 2010 par la vérification des sites de la micro-région (sauf sur la commune de Cannelle qui n'a pas souhaité prendre part à ce travail) suivi, en 2011, par une première prospection-inventaire sur les communes d'Ambiegna et de Casaglione et en 2012, par une seconde prospection-inventaire sur les communes de Sant'Andria et de Sari d'Orcinu.

2 Les recherches sur le territoire d'Arro se sont déroulées entre mars et juillet 2013. Nous avons couvert environ $94 \%$ du territoire de cette commune qui s'étend sur 880 ha dont 728 ha de bois et de maquis et inventorié 29 sites et indices de site couvrant toutes les périodes chronologiques de la Préhistoire à l'époque contemporaine, exception faite du Moyen Âge : quatre pour la Préhistoire, cinq pour la Préhistoire et/ou Protohistoire, deux pour la Protohistoire, deux pour l'Antiquité, deux pour l'époque moderne, treize pour l'époque contemporaine et un site d'époque indéterminée. Quant aux recherches sur le territoire de Calcatoggio, elles se sont déroulées de juillet à décembre 2013. Nous avons parcouru $74 \%$ du territoire communal qui s'étend sur 2265 ha de bois, de maquis, de plaines et de pâturages. Nous y avons inventorié 31 sites et indices de site couvrant toutes les périodes chronologiques de la Préhistoire à la période contemporaine, exception faite du Moyen Âge : huit pour la Préhistoire, cinq pour la Préhistoire et/ou la Protohistoire, six pour la Protohistoire, trois pour l'Antiquité, deux pour la période moderne, cinq pour la période contemporaine et deux diachroniques (couvrant plusieurs périodes chronologiques) (fig. 1). 
3 Les sites et indices de site archéologiques répertoriés lors de cette campagne 2013 s'élèvent au nombre de 61 et couvrent toutes les périodes, mais avec des disparités. Ces disparités résultent de la morphologie des territoires parcourus, puisque nous avons vu que chaque période avait ses zones préférentielles d'installation. La morphologie des sites rencontrés est d'ailleurs très variée et témoigne des activités humaines au cours des millénaires. Cette prospection-inventaire diachronique avait pour but de mieux connaître les territoires d'Arro et de Calcatoggio et d'y appréhender leur fort potentiel archéologique. Cette démarche a également permis de faire ressortir les facteurs physiques qui ont concouru à l'installation des populations, en mettant en exergue les critères géographiques et géologiques auxquels s'ajoutent des données d'ordres ethnologiques (modes de sépulture, etc).

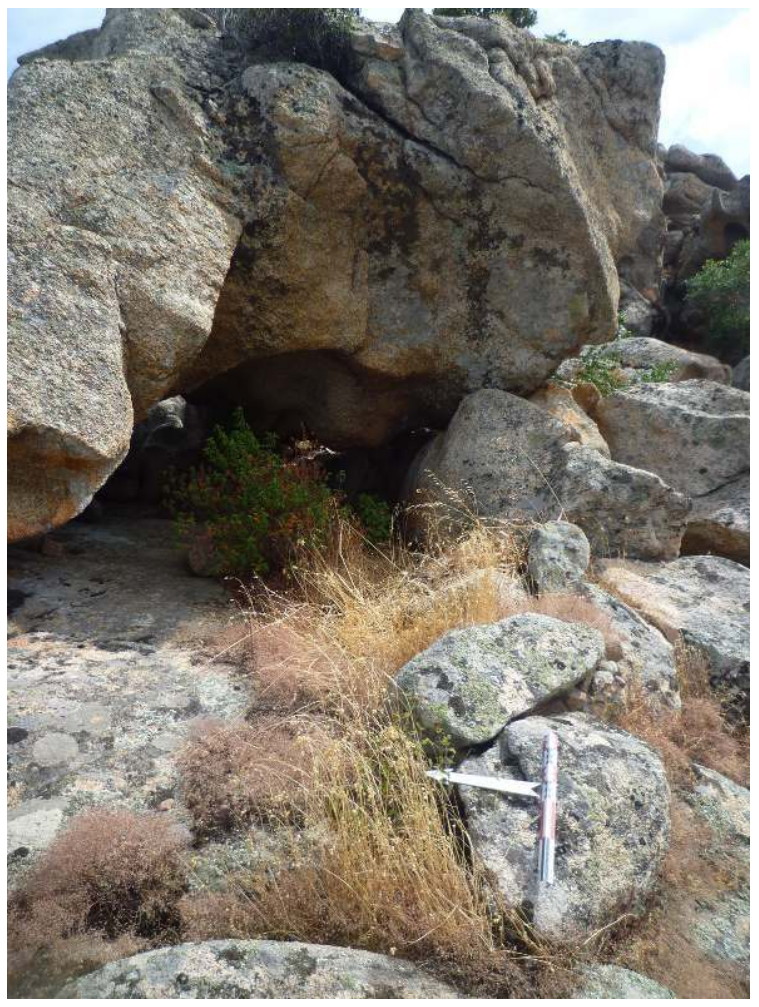

Fig. 1

Calcatoggio, lieu-dit Borgomani, abri aménagé.

Marie-Andrée Gardella (AUT), 2013.

INDEX

Index chronologique : Préhistoire, ép. contemporaine, Antiquité operation Prospection diachronique (PRD)

Index géographique : Corse, Corse-du-Sud (2A), Arro, Calcatoggio 
AUTEURS

MARIE-ANDRÉE GARDELLA

AUT 